\title{
A case Report of Multisystem Inflammatory Syndrome in Children (MIS-C) in Infant
}

\author{
Tengku Benyamin ${ }^{1}$, Ririe Fachrina Malisie ${ }^{2}$ \\ Iamnbenytgku.mhd@gmail.com \\ ${ }^{I}$ Resident of Department of Child Health, Medical School, Universitas Sumatera Utara/ Universitas Sumatera Utara Hospital/ H. Adam \\ Malik Hospital, Jl. dr. Mansyur No. 5, Medan 20155, Indonesia \\ ${ }^{2}$ Pediatric Emergency and Intensive Care Consultant of Department of Child Health, Medical School, Universitas Sumatera \\ Utara/Universitas Sumatera Utara Hospital/H. Adam Malik Hospital, Jl. dr. Mansyur No. 5, Medan 20155, Indonesia
}

\begin{abstract}
Background: The multisystem inflammation associated with COVID-19 is marked by positive reverse transcriptase polymerase chain reaction (RT-PCR) tests for viral RNA, antigen / antibody, or exposure to COVID-19 between 4 weeks before symptoms appear.

Case Presentation: A girl 2 months and 27 days old was clinically diagnosed as multisystem inflammatory syndrome (MIS-C) based on criteria from CDC, RCPH, WHO. The main complaint was shortness of breath had been experienced since 4 days ago, cough was experienced since 4 days ago, the history of fever was experienced since 4 days Patients had experienced diarrhea for 2 days. Vomiting was currently absent. The patient has dyspnoe with minimal retraction from the inspection of the chest and auscultation was heard rales in both of lung. The laboratory result of anti COVID-19 test was reactive IgG and negative swab PCR SARS CoV-2 test, and from marker inflammation showed increase. From the chest X-ray showed infiltrates in both of lungs.

Conclusion: This is a case reported of the multisystem inflammatory syndrome in 2 months 27 days old infant and Diagnostic approach MIS-C have based on criteria from CDC, RCPH and WHO.
\end{abstract}

Keywords: MIS-C, Multisystem inflammatory syndrome in children, COVID-19

\section{Introduction}

In early December 2019, the 2019 corona virus disease (COVID-19) was first famous in Wuhan China with flu-like symptoms. The virus identified as a new strain of the coronavirus is called SARS CoV-2 which has symptom of severe acute respiratory syndrome coronavirus (Siripanthong et al, 2020). The spread of COVID19 infection is very fast that occurs in the world, nowadays more than 2,000,000 cases of death have occurred in humans so that COVID-19 has become an urgent health problem (Oberweis et al, 2020). In Indonesia, the incidence of COVID-19 is 1.210 .703 people with 32.936 deaths on February $13^{\text {th }}, 2021$ (Kemenkes RI).

The main targets of SARS CoV-2 are the respiratory tract, lungs and other organs who have angitensin converting enzyme - 2 (ACE-2) receptor. The disease is spread from person to person through airborne droplet transmission or direct contact. Up to 14 days it takes for the disease to cause symptoms (Sanna et al, 2020). 

multi-organ dysfunction. In addition, complications that can arise in children with COVID 19 infection are multisystem inflammatory syndrome (Grimaud et al, 2020), that occurs 4-6 weeks after SARS CoV-2 infection and its characterized by cytokine storm innate and adaptive immune cells (Brodsky et al, 2020). The multisystem inflammation associated with COVID-19 is marked by positive reverse transcriptase polymerase chain reaction (RT-PCR) tests for viral RNA, antigen / antibody, or exposure to COVID-19 between 4 weeks before symptoms appear (Sanna aet al, 2020).

Here, we report the case of a 2 months and 27 days old girl who was clinically diagnosed as MIS-C in infant with anti COVID-19 test result was reactive IgG and negative swab PCR SARS CoV-2 test.

\section{Case Report}

A girl, 2 months 27 days old, admitted to emergency room at H. Adam Malik Medan general hospital on November 20th, 2020 with a main complaint was shortness of breath. Shortness of breath had been experienced since 4 days ago and the more frequent in the last 2 days. Cough was experienced since 4 days ago. Fever was not experienced at the admitted but the history of fever was experienced since 4 days ago for 2 days, the peak of temperature was $38,5^{0} \mathrm{C}$ with 1-2 time increasing temperature in a day. Patients had experienced diarrhea for 2 days with no mucos and no blood. The patient had a history of vomiting. No history of contact with people with COVID-19 and no family history who experiencing to same main complaint.

The patient was born by sectio caesarean due to pregnancy of gemelli's mother, was born crying immediately, no cyanosis, motion was not active with a birth weight of 2.500 gr. The history of mother going out of town was denied. The mother never tested the rapid antigen or antibody examination of COVID-19.

Physical examination on the chest, she experienced dyspnoe with minimal retraction from inspection and from auscultation was heard rales in both oh lungs. From the laboratory result showed anti COVID-19 result was reactive Ig G and negative swab PCR SARS Co-V-2 test. Inflammation marker were high (White blood cell 27.530/uL, D-dimer $12.800 \mathrm{ng} / \mathrm{dL}$, procalcitonine 7,91 ng/mL, CRP 1,4 mg/dL, ferritin >2.000 $\mathrm{ng} / \mathrm{mL}$ ). From the chest $\mathrm{x}$-ray showed infiltrate in the bilateral perihiler and right pericardial (figure 1). Caradiac enzyme showed CK-MB was high (48 U/L) and troponin $\mathrm{T}$ was normal (<40 ng/L). Patient did echocardiography examination with normal structure and function of the heart. This patient had gotten metilprednisolon $4 \mathrm{mg} /$ day for 5 days. 


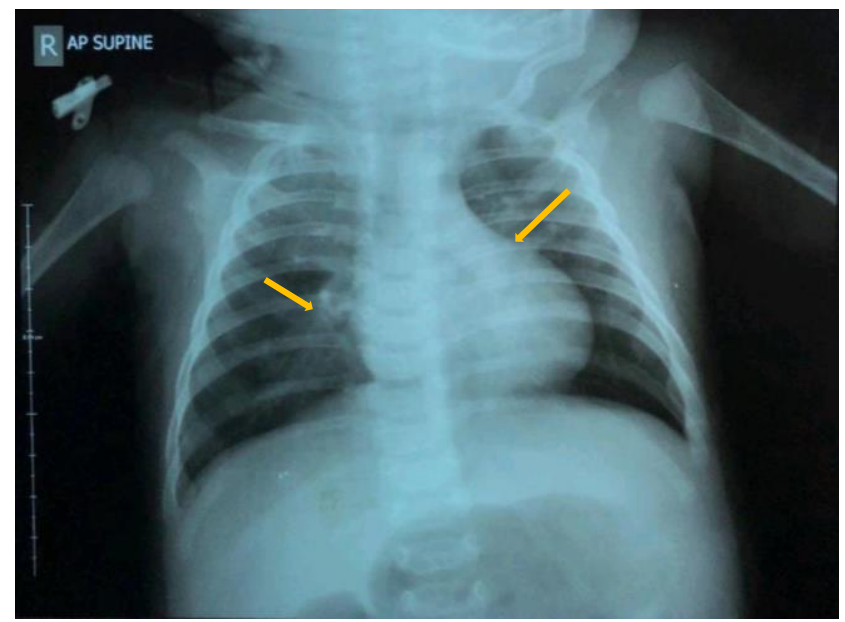

Figure 1. Infiltrate appears in the bilateral perihiler and right pericardial

\section{DISCUSSION}

MIS-C (mulitisystem inflammatory syndrome in children) is an inflammatory syndrome in children who experience inflammation of the liver, lungs, kidneys, brain, skin, eyes and gastrointestinal organs (CDC, 2020). Center for Disease Control and Prevention (CDC), UK's Royal College of Pediatrics and Child Health and WHO (table 1) characterize the MIS-C in COVID-19 infections that test positive for SARS CoV-2 by RT-PCR for viral RNA, antigen, antibodies or other exposure to COVID -19 in the 4 weeks before the onset of symptoms. The investigation of this emerging inflammatory disease in children ongoing COVID-19 named paediatric inflammatory multisystem syndrome (PIMS) or MIS-C (Belot et al, 2020).

Children with MIS-C have fever symptoms and a variety of visible symptoms such as abdominal pain, vomiting, diarrhea, neck pain, rash, bleeding in the eyes, feeling very tired (CDC, 2020). The clinical presentation of MIS-C with COVID-19 is widely reported with significant gastrointestinal symptoms, cardiac disease, mild or no respiratory symptoms, and an incidence of rash, pink eye, and changes in the oral mucous membrane (Hennon et al, 2020). The main symptoms of MIS-C that arise are persistent fever (more than 24 hours to several days), weakness, loss of appetite and or not wanting to drink enough fluids, with symptoms that occur very quickly and are worse (Boston Children's Hospital, 2020).

All three definitions include presence of fever, laboratory evidence of inflammation, and multisystem organ involvement without alternative plausible diagnoses, as well as evidence of COVID-19 infection or recent exposure to a COVID-19 case (Sperotto et al, 2020). The patient in this case has been known about the symptoms that had experienced by the patient. They were the COVID-19's symptoms especially the MIS-C's symptoms based on CDC. One of the main problems was shortness of breath that had experienced since 4 days ago and the more frequently in the last 2 days. The cought had been experienced by the patient also and 
Table 1. The criteria MIS-C based on RCPH, CDC and WHO (Sperotto et al, 2020)

\begin{tabular}{|c|c|c|}
\hline $\begin{array}{l}\text { Royal College of Paediatrics and Child } \\
\text { Health, UK }\end{array}$ & $\begin{array}{l}\text { Centers for Disease Control and } \\
\text { Prevention }\end{array}$ & World Health Organization (WHO) \\
\hline $\begin{array}{l}\text { A child presenting with persistent fever } \\
\text { (> } 38.5^{\circ} \text { C), inflammation (neutrophilia, } \\
\text { elevated CRP, and lymphopenia) and } \\
\text { evidence of single or multiorgan } \\
\text { dysfunction (shock, cardiac, respiratory, } \\
\text { kidney, gastrointestinal, or neurological } \\
\text { disorder) with additional features*. } \\
\text { This may include children fulfilling full or } \\
\text { partial criteria for KD. } \\
\text { Exclusion of any other microbial cause, } \\
\text { including bacterial sepsis, staphylococcal } \\
\text { or streptococcal shock syndromes, } \\
\text { infections associated with myocarditis } \\
\text { such } \\
\text { as enterovirus (waiting for results of these } \\
\text { investigations should not delay seeking } \\
\text { expert advice). } \\
\text { SARS-CoV-2 RT-PCR test results may be } \\
\text { positive or negative. } \\
\text { *Additional features: } \\
\text { Clinical: } \\
\text { Most: oxygen requirement, hypotension } \\
\text { Some: abdominal pain, confusion, } \\
\text { conjunctivitis, cough, diarrhea, headache, } \\
\text { lymphadenopathy, mucus membrane } \\
\text { changes, neck swelling, rash, respiratory } \\
\text { symptoms, sore throat, swollen hands and } \\
\text { feet, syncope vomiting; } \\
\text { Laboratory: } \\
\text { All: abnormal fibrinogen, high D-dimers, } \\
\text { high ferritin, hypoalbuminemia; } \\
\text { Some: acute kidney injury, anemia, } \\
\text { thrombocytopenia, coagulopathy, high } \\
\text { IL-10, high IL-6, proteinuria, high CK, } \\
\text { high LDH, high TG, high troponin, } \\
\text { transaminitis; }\end{array}$ & $\begin{array}{l}\text { An individual aged < } 21 \text { years presenting } \\
\text { with fever*, laboratory evidence of } \\
\text { inflammation**, and evidence of } \\
\text { clinically } \\
\text { severe illness requiring hospitalization, } \\
\text { with multisystem ( } \geq 2 \text { ) organ } \\
\text { involvement } \\
\text { (cardiac, renal, respiratory, hematologic, } \\
\text { gastrointestinal, dermatologic or } \\
\text { neurological); } \\
\text { AND } \\
\text { No alternative plausible diagnoses; } \\
\text { AND } \\
\text { Positive for current or recent SARS-CoV- } \\
2 \\
\text { infection by RT-PCR, serology, or antigen } \\
\text { test, or COVID-19 exposure within } \\
4 \text { weeks prior to the onset of symptoms. } \\
\text { *Fever } \leq 38{ }^{\circ} \mathrm{C} \text { for } \geq 24 \text { h, or report of } \\
\text { subjective fever lasting } \geq 24 \text { h. } \\
\text { **Including, but not limited to, one } \\
\text { ormore of } \\
\text { the following: an elevated CRP, ESR, } \\
\text { fibrinogen, procalcitonin, d-dimer, } \\
\text { ferritin, } \\
\text { LDH, or IL-6, elevated neutrophils, } \\
\text { reduced lymphocytes and low albumin. } \\
\text { Additional comments: } \\
\text { Some individuals may fulfill or partial } \\
\text { criteria } \\
\text { for KD but should reported if they meet } \\
\text { the } \\
\text { case definition for MIS-C; } \\
\text { Consider MIS-C in any pediatric death } \\
\text { with } \\
\text { evidence of SARS-Cov- } 2 \text { infection. }\end{array}$ & $\begin{array}{l}\text { Children and adolescents } 0-19 \text { years of } \\
\text { age } \\
\text { with fever } \geq 3 \text { days; } \\
\text { AND two of the following: } \\
\text { 1. Rash or bilateral non-purulent } \\
\text { conjunctivitis or muco-cutaneous } \\
\text { inflammation signs (oral, hands or feet). } \\
\text { 2. Hypotension or shock. } \\
\text { 3. Features of myocardial dysfunction, } \\
\text { pericarditis, valvulitis, or coronary } \\
\text { abnormalities (including echo findings or } \\
\text { elevated troponin/NT-proBNP), } \\
\text { 4. Evidence of coagulopathy (by PT, PTT, } \\
\text { elevated d-dimers). } \\
\text { 5. Acute gastrointestinal problems } \\
\text { (diarrhea, } \\
\text { vomiting, or abdominal pain). } \\
\text { AND } \\
\text { Elevated markers of inflammation such as } \\
\text { ESR, C-reactive protein, or procalcitonin. } \\
\text { AND } \\
\text { No other obvious microbial cause of } \\
\text { inflammation, including bacterial sepsis, } \\
\text { staphylococcal or streptococcal shock } \\
\text { syndromes. } \\
\text { AND } \\
\text { Evidence of COVID-19 (RT-PCR, } \\
\text { antigen } \\
\text { test or serology positive), or likely contact } \\
\text { with patients with COVID-19. } \\
\text { Consider this syndrome in children with } \\
\text { features of typical or atypical KD or toxic } \\
\text { shock syndrome }\end{array}$ \\
\hline
\end{tabular}

Echo and ECG: myocarditis, valvulitis, pericardial effusion, coronary artery dilation;

CXR: patchy symmetrical infiltrates,

pleural

effusion;

Abdo USS: colitis, ileitis,

lymphadenopathy,

ascites, hepatosplenomegaly;

CT chest: as for CXR. May demonstrate

coronary artery abnormalities if with

contrast.

APTT activated partial thromboplastin time, CK creatine kinase, COVID-19 coronavirus disease 2019, CXR chest X-ray, CRP Creactive protein, echo echocardiography, ESR erythrocyte sedimentation rate, IL interleukin, KD Kawasaki disease, LDH lactic acid dehydrogenase, MIS-C multisystem inflammatory syndrome in children, NT-proBNP N-terminal pro-B-type natriuretic peptide, PT prothrombin time, PTT partial thromboplastin time, RT-PCR reverse transcriptase-polymerase chain reaction, SARS-CoV-2 severe acute respiratory syndrome coronavirus 2 , TG triglycerides 
The shortness of breath as sign of severe acute respiratory syndrome coronavirus 2 (SARS-CoV-2) 71

infection. Pathogenesis of severe acute respiratory syndrome coronavirus 2 (SARS-CoV-2) infection associated with angiotensin-converting enzyme 2 (ACE2) receptor of epithelial cells. Particles of virus bind to angiotensinconverting enzyme 2 (ACE2) receptor of epithelial cells with its spike protein to reach intracellular then they replicate and giving rise to clinical manifestations. The virus infect alveolar type II cells (type II pneumocytes) in the alveolus of lung after reaching alveolus. This process causes apoptosis and damage of alveolar type II cells. The role of immunity also affects damage cells which may lead to cytokine storm that is characterized by over-production of cytokines and cause systemic inflammatory response or acute respiratory distress syndrome (ARDS) (Singh et al, 2020). Actually, the pathophysiology of MIS-C in COVID-19 is still unclear, but a theory regarding immune dysregulation has also explained MIS-C in COVID-19. Early infection with SARS CoV-2 was usually asymptomatic but sometimes had mild symptoms in children. The second phase or pulmonary phase occurs activate macrophages with stimulation of T-Helper cells and this condition characterized by severe conditions. Although, mild symptom or no symptom occur in children. The third phase cytokines release causing excessive immune response associated with inflammatory syndrome in COVID-19 (Nakra et al, 2020).

Another explanation regarding the pathophysiology of MIS-C is described by the study by Rowley et al. SARS CoV-2 antibodies originate from the second week after infection, but the presence of these antibodies does not lead to resolution of infection. A recent study also reported a neutralization of antibody activity in MIS-C compared to adult COVID-19 patients causing acute respiratory failure. The virus was not detected in the respiratory tract of patients with MIS-C. Although the presence of SARS CoV-2 specific T cells in peripheral blood vessels has been reported in adult patients but not in children who have reported reactive T cells (Rowley et al, 2020). That theory apropritate with data in this case, the patient had Ig G reactived based on antibody examination with negative rapid molecular COVID-19 although there was no history when the patient was transmitted the infection. The infection markers examination in this case has also increased (D-Dimer 12.800 ng/dL, procalcitonine, 7,91 ng/mL, CRP 1,4 g/dL, Ferritin >2.000 ng/mL, although fibrinogen was normal).

The fever had not been experienced at the pasient admitted to emergency room but the history of fever had been experienced by the patient since 4 days ago for 2 days, with the peak of temperature was $38,5^{\circ} \mathrm{C}$. It occurred fluctuating with frequency 1- 2 times peak temperature in a day. The patient had diarrhea in 2 days with a frequency of 5 times / day, water > dregs, no mucus, no blood. She also had a history of vomiting since 1 day ago with a frequency of once containing milk and no blood. The all symptoms according to the MIS-C's criteria based on CDC. The patient was 2 months and 27 days with clinical symptoms fever, severe illness necessitating hospitalization and two organ systems affected.

From the laboratory result of this case, the result of rapid test Ig G for COVID-19 was reactive with both of swab rapid moleculer examination were negative. Reactive rapid test COVI-19 IgG meant previous infection of COVID-19 (University of Birmingharm, 2020), and actually it showed that the patient had exposed 

had never been contact to confirmed COVID-19 patient. The history of mother going out of town was denied. The mother had never tested the rapid antigen or antibody examination of COVID-19.

Basically, antibody based diagnosis have historically been used in the detection of viruses and immunoglobulin testing methods have also found applications in this diagnosis. The infection caused by all coronaviruses have some similarities at the level of immunological response from the human body. Acute phase is detectable antibody specific responses against infections but it still observed, this condition from 1 up to 7 days. IgM expression began 3 up to 6 days post infection and It peaked for 9 up to 15 days of the occurrence of symptoms. IgG expression began post 10 days of occurance symptoms and it peaked from 20 up to 30 days after symptoms. Determining the time-window for symptom onset and detection of antibodies have been big steps following the successful employment of antibody-based diagnosis. Both viral RNA and proteins (antigens) are detected in the nasopharyngeal samples soon after appearing symptom especially spike protein (timedependent prescence of viral RNA/viral antigen in nasopharyngeal samples or immunoglobulins in serum of COVID-19) (Augustine et al, 2020).

The consideration about reactive IgG may be caused by utero transmission. For in utero transmission, the pathogen must be present in blood and be able to cross the placenta and infect the fetus. Viraemia secondary to SARS-CoV-2 appears rare theoritocally. In the few cases in which viraemia occurs, allowing the virus to reach the placenta, it may be possible to cross the placenta and infect the fetus, as the ACE- 2 receptor has been identified in both placental and fetal tissues. While SARS-CoV- 2 infection has been reported to be detected in a small number of infants born to pregnant women with COVID-19, determination of in utero infection is complex, and requires sampling of appropriate tissues or fluids near the time of birth. Most studies have not collected appropriate samples with proper timing (Rowley et al, 2020).

From the another labotories result that supporting make the diagnosing of MIS-C were found CRP, fibrinogen, D-Dimer, procalcitonin and ferritin in higher than normal value. CRP 1,4 mg/dl, fibrinogen 110 $\mathrm{mg} / \mathrm{dL}$, D-Dimer $12.800 \mathrm{mg} / \mathrm{dL}$, procalcitonine 7,91 ng/mL, lactate acid 3,8 mmol/L and ferritin > 2.000 ng/mL. These value appropriate with the CDC criteria diagnosing of MIS-C, although the swab rapid molecular result negative. Based on The Royal College of Paediatrics and Child Health, UK (RCPH) (Sperotto et al, 2020) explains some criteria MIS-C, one of them is SARS-CoV-2 RT-PCR test result may be positive or negative. Study by Davies et al. reported about SARS CoV-2 IgG serology in PCR negative patients were 24 patient (n =25), and they were PIMS-TS (pediatric inflammatory multisystem syndrome-temporally associated)

The chest radiologic examination on November 21, 2020 have showed bilateral infiltrate especially right lung and on November 24, 2020 have showed the infiltrate appears in the bilateral perihiler and right pericardial. It has met the RCPH criteria. Echocardiography examination showed normal structure of the heart with increasing the cardiac enzyme (Troponin $\mathrm{T}<40 \mathrm{ng} / \mathrm{L}$ and CKMB $48 \mathrm{U} / \mathrm{L}$ ). Echocardiography examination 

showed decreasing stroke volume (SV) and increasing stroke volume resitance index (SVRI) that they were known from USCOM examination \{SVI: 21 (31-40), SVRI: 1632 (919-1464)\}

WHO has described the association dysfunction with more specific cardiac parameters, including the presence of myocardial dysfunction, pericarditis, valvulitis, coronary disorders seen on echocardiography or through increased BNP (brain natriuretic peptide). Several assessments in MIS-C are based on clinical manifestations (fever, abdominal complaints, hypotension, shock), laboratory findings (bandemia, lymphopenia, increased information markers and D-Dimer) and the presence of all heart problems (left ventricular cytolic dysfunction affect the presence of inflammation and an increase in BNP / troponin). The presence of arterial aneurysms and conduction disturbances are present in about $20 \%$ of patients and this also results in atrioventricular block (Beroukhim et al, 2020).

Treatment recommendations based on the American Academy of Pediatrics are compiled in a recommendation guide for MIS-C patients. IVIG administration 1-2 g / KgBW. Steroids may be given 2-30 mg / $\mathrm{KgBW}$ of methylprednisolone / day based on the severity of the disease. Interleukin 1 receptor antagonist (anakinra), given 2-10 mg / KgBW / day subcutaneously or intravenously divided over 6 to 12 hours. Steroids and interleukin receptor antagonists are tapered off within 3 weeks. Antibiotics can be given as early intervention with various etiologies of the cause. Assessment of the risk of blood clots and prophylactic recommendations can be given (low-dose aspirin) (Kohli et al, 2020). Evaluation of treatment on MIS-C through inflammatory markers, markers of heart examination (troponin, creatinine kinase-MB, BNP), electrocardiography. In this case the patient had gotten metilprednisolon $4 \mathrm{mg} /$ day for 5 days.

\section{Conclusion}

This is a case reported of the multisystem inflammatory syndrome in 2 months 27 days old infant. Diagnostic approach MIS-C have based on criteria from CDC, RCPH and WHO. This rapid antibody IgG was reactived with negative rapid molecular antigen test. The main complaint was the shortness of breath, as a sign of SARSCoV-2 infection with bronkopneumonia result in chest radiologic imaging, with gastrointestinal track problem. Cardiac manifestation with increasing cardiac enzyme (CKMB) as a marker dysfuntion of myocardial (myokarditis) while tropnine $\mathrm{T}$ and echocardiography examination result showed normal structure and function of the heart.

\section{References}

Augustine, R., Das, S., Hasan, A., Abilash., Salam., S,A., Augustine, P., et al. 2020. Rapid antibody-based COVID-19 mass surveillance: relevance, challenges, and prospects in a pandemic and post-pandemic world. Journal of Clinical Medicine, p. 3372-3397.

Belot, A., Antona, D., Renolleau, S., Javohey, E., Hentgen, V., Angoulvant, F., et al. 2020. SARS-CoV-2-related paediatric inflammatory multisystem syndrome, an epidemiological study, France, 1 March to 17 May 2020. Euro Surveillance, p. 1-6.

Beroukhim, R,S., Friedman, K. 2020. Children at risk multisystem inflammatory syndrome and COVID-19. Journal of the American College of Cardiology, p.1271-1274. 
Brodsky, N,N., Ramaswamy, A., Lucas, C,L., 2020. The mystery of MIS-C post-SARS-CoV-2 infection. Trends in Microbiology, p. 956- ${ }^{155 N: 2708-3578 \text { (0nline) }}$ 958.

Multisystem Inflammatory Syndrome in Children (MIS-C). 2020. Centre for Disease Control and Prevention. Available From: https://www.cdc.gov/mis-c/

Devies, P., Evans, C., Kanthimathinathan, H,K., Lilie, J., Bierley, J., Waters, G., et al. 2020. Intensive care admissions of children with paediatric inflammatory multisystem syndrome temporally associated with SARS-CoV-2 (PIMS-TS) in the UK: a multicentre observational study. The Lancet Child and Adolescent Health, p. 669-677.

Grimaud, M., Starck., J, Levy., M, Marais., C, Chareyre., J, Khraiche., D, et al. 2020. Acute myocarditis and multisystem inflammatory emerging disease following SARS-CoV-2 infection in critically ill children. Annal of Intensive Care, p. 69.

Hennon, TR., Penque, M,D., Abdul, A, R., Aliibrahim, O,S., McGreevy, M,B., Prout, A,J., et al. 2020. COVID-19 associated multisystem inflammatory syndrome in children (MIS-C) guidelines; a western new york approach. Progress in Pediatric Cardiology, p. 101232.

Kohli, U., Lodha, R. 2020. Cardiac involvement in children with covid-19. Indian Pediatrics, p.1-5.

Multisystem Inflammatory Syndrome in Children (MIS-C). 2020. Boston Children's Hospital. Available From: http://www.childrenshospital.org/conditions-and-treatments/conditions $/ \mathrm{m} / \mathrm{mis}-\mathrm{c}$

Nakra, N,A., Blumberg, D,A., Guerra, A,H., Laksminrusimha, S. 2020. Multi-system inflammatory syndrome in children (mis-c) following sars cov-2 infection: review of clinical presentation, hypothetical pathogenesis, and proposed management. Children (Basel), p. 69.

Oberweis, M,L., Codreanu, A., Boehm, W., Olivier, D., Pierron, C., Tsobo, C., et al. 2020. Pediatric Life-Threatening Coronavirus Disease 2019 With Myocarditis, p.147-149

Rowley, A,H., Shulman, S,T., Arditi, M. 2020. Immune pathogenesis of COVID-19 related multisystem inflammatory syndrome in children. The Journal of Clinical Investigation, p. 5619-5621.

Sanna, G, Serrau, G., Bassareo, P, P., Neroni, P., Fanos, V., Marcialis, M, A. 2020. Children's heart and COVID-19: Up-to-date evidence in the form of a systemic review. Europian Journal of Pediatric, p. 1079-1087.

Singh ,V,K., Mishra, A., Singh, S., Kumar, P., Singh, M., Jaganath, C., et al. 2020. Emerging prevention and treatment strategies to control covid-19. Pathogens, p. 501-516.

Siripanthong, B., Zazarian, S., Muser, D., Deo, R., Santangeli, P., Khanji, M,Y., et al. 2020. Recognizing COVID-19- Related Myocarditis: The Possible Pathophysiology and Proposed Guideline for Diagnosis and Management. Heart Rhythm, p. 1-9.

Sperrotto, F., Friedman, K, G., Son, M,B,F., Vanderpluym, C,J., Newburger, J,W., Dionne, A. 2020. Cardiac manifestations in SARSCoV-2-associated multisystem inflammatory syndrome in children: a comprehensive review and proposed clinical approach. European Journal of Pediatric, p.307-322.

University of Birmingham. 2020. COVID-19 in pregnancy (PregCOV-19LSR). Available From: https://www.birmingham.ac.uk/research/who-collaborating-centre/pregcov/about/mother-to-child-transmission.aspx

Update COVID-19. 2021. Infeksi Emerging. Available From: https://covid19.kemkes.go.id/category/situasi-infeksi-emerging/info-corona-virus/\#.Xw19-ygzbDd 